\title{
Hyper-concentrated flows in tributaries of the middle Yellow River
}

\author{
H. Hashimoto, H. Takaoka \& S. Ikematsu \\ Department of Civil Engineering, Kyushu University, Japan
}

\begin{abstract}
The purpose of the present study is to examine resistance rule and sediment transport characteristics of hyper-concentrated flows in tributaries of the middle Yellow River. The Kuye, Dali, Tuwei and Jialu Rivers are selected as the study area. Laboratory experiments of hyper-concentrated flows are made in an open channel, using silt and sand as flowing material. Field data of flow and sediment discharge of the rivers are obtained. The sediment-water mixture flow model proposed by Hashimoto and Hirano is found to be valid for the hyperconcentrated flows in the Kuye River and laboratory experiments with fine sand. Keywords: Yellow River, hyper-concentrated flow, flow resistance, sediment transport.
\end{abstract}

\section{Introduction}

The Yellow River basin has serious problems of flood and irrigation due to hyper-concentrated flows from the tributaries of the middle river reach (Wan and Wang [5]). In order to solve these problems, it is important to estimate flow resistance and sediment transport in the hyper-concentrated flows. There are some works on these subjects (e.g. Wan and Wang [5] and Mantz [6]). However, the less model can explain satisfactorily flow resistance and sediment transport. The purpose of the present study is to find a flow model for flow resistance and sediment transport characteristics in the hyper-concentrated flows. The Kuye, Dali, Tuwei and Jialu River are selected as the study area (Fig. 1). We visited the Kuye and Dali River in 2002. First we investigate characteristics of bed sediments in these rivers. Second, we make laboratory experiments of hyperconcentrated flows in an open channel, using silt and sand as flowing material. 


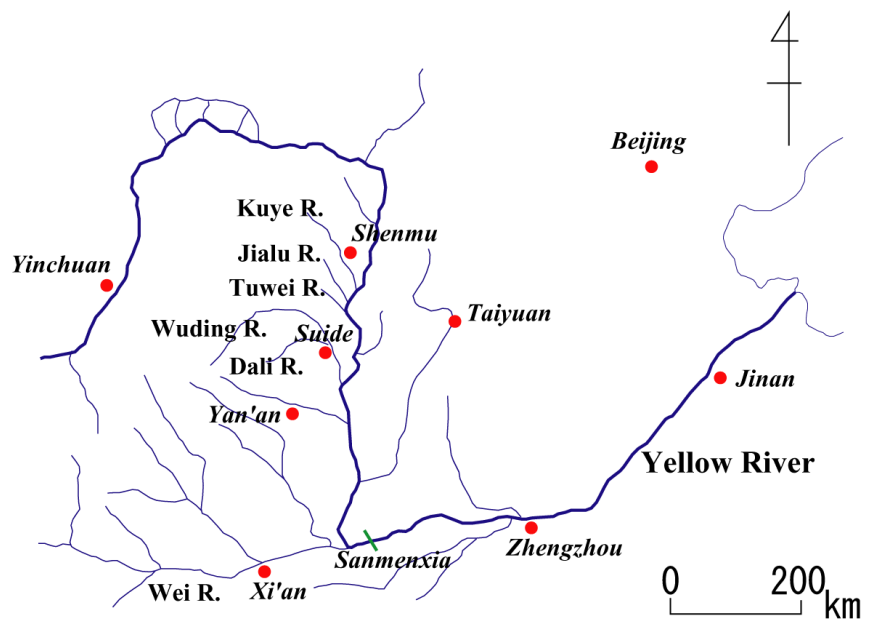

Figure 1: $\quad$ Main tributaries of the middle Yellow River.

Third, we obtain field data of flow and sediment discharge in the rivers (Yellow River Conservancy Commission [1]). Using the sediment-water mixture flow model proposed by Hashimoto and Hirano [2, 3], we explain the hyperconcentrated flow behaviour in an experimental flume and the tributaries of the middle Yellow River.

\section{Characteristics of river bed sediments}

We visited the Kuye and Dali River on August 14 to 20, 2002 and took the river bed and bank sediments. The Kuye and Dali River basins are significant erosion areas in the middle reaches of the Yellow River ( $\mathrm{Li}$ [7]).

The Kuye River is $242 \mathrm{~km}$ long with basin area of $8,706 \mathrm{~km}^{2}$ and bed slope of $1 / 510$ to $1 / 290$. The Dali River, on the other hand, is $170 \mathrm{~km}$ long with basin area of $3,906 \mathrm{~km}^{2}$ and bed slope of $1 / 270$ to $1 / 80$.

Figs. 2 (a) and (b) show the grain size distribution of bed and bank sediments in the Kuye and Dali River, respectively. K-1, 2, 3 and 4 in fig. 2(a) indicate the positions of the sediments in the Kuye River and D-1, 2, 3 and 4 in fig. 2(b) indicate the positions of the sediments in the Dali River. It is found that K-1 is silt, K-2 coarse sand, K-3 fine sand and K-4 very fine sand, and D-1, 2 and 3 are silt and D-4 very fine sand. Since K-1 and D-4 denote bank sediments, bed sediments of Kuye and Dali River are sand and silt, respectively.

\section{Experiments of hyper-concentrated flows}

Bed sediments are sand in the Kuye River and silt in the Dali River. Using silt and sand as flowing material, we make experiments of hyper-concentrated flows in an open channel to investigate flow resistance and sediment transport characteristics. 


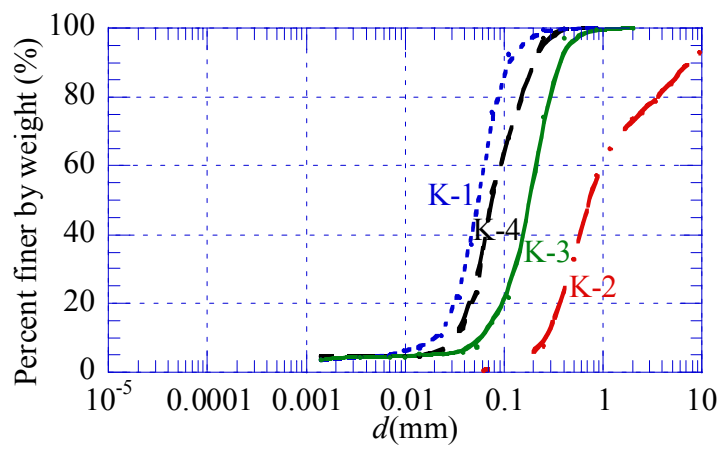

(a) Kuye River

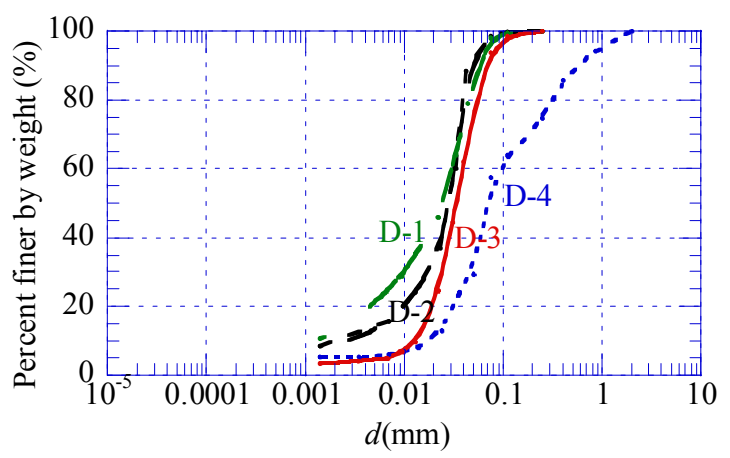

(b) Dali River

Figure 2: Grain size distribution of river bed and bank sediments.

\subsection{Experimental method}

An experimental flume used is $15 \mathrm{~cm}$ wide and $7 \mathrm{~m}$ long with a fixed bed of plywood, as shown in fig. 3. The bed slope is set at the angle of 3 degrees. A tank with diameter of $136 \mathrm{~cm}$ and depth of $80 \mathrm{~cm}$ is placed at the downstream end of the flume. We agitate a mixture of sediment and water in the tank and then transport it through the acrylic pipe to the upstream end by a pump. As a result, the mixture circulates through the flume, tank and pipe. Fine sand, very fine sand and silt are used as flowing material.

We make two kinds of experiments; one is for measurement of velocity profiles, and the other for friction coefficient and sediment discharge. Table 1 shows the experimental conditions. Here, $d=$ average grain diameter; $\sigma / \rho=$ specific gravity of sediment grains; $C_{0}=$ initial sediment concentration in the tank; $C_{T}=$ sediment concentration in mixture flow; $q_{t}=$ flow discharge per unit width; $h=$ flow depth and $v=$ average flow velocity. In the former experiments, velocity profiles are measured with a pitot tube. In the latter experiments, flow and sediment discharge are measured by catching sediment-water mixture flow 
at the downstream end of the flume. Flow depth is also measured with a point gage. From these measurements, we estimate friction coefficients and nondimensional sediment discharge.

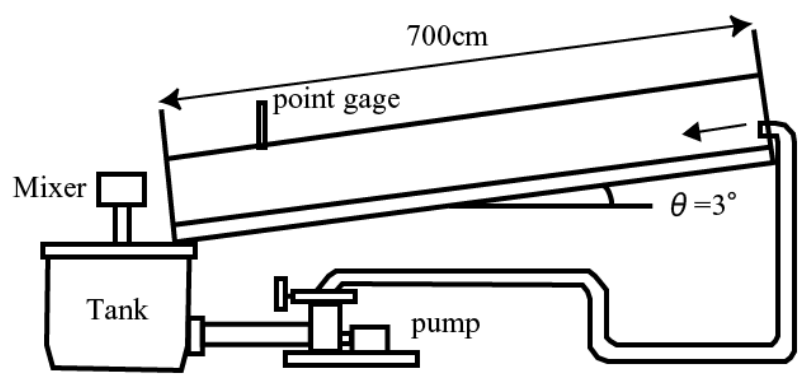

Figure 3: Experimental flume.

Table 1: $\quad$ Experimental conditions.

\begin{tabular}{|c|c|c|c|}
\hline & silt & very fine sand & fine sand \\
\hline$d(\mathrm{~mm})$ & 0.016 & 0.067 & 0.17 \\
\hline$\sigma / \rho$ & 2.708 & 2.64 & 2.62 \\
\hline$C_{0}$ & $0.100-0.498$ & $0.050-0.401$ & $0.049-0.301$ \\
\hline$C_{T}$ & $0.088-0.369$ & $0.046-0.404$ & $0.059-0.296$ \\
\hline$q_{t}\left(\mathrm{~cm}^{2} / \mathrm{s}\right)$ & $169-266$ & $198-257$ & $229-296$ \\
\hline$h(\mathrm{~cm})$ & $1.45-3.42$ & $1.30-1.81$ & $1.74-2.11$ \\
\hline$v(\mathrm{~cm} / \mathrm{s})$ & $77-148$ & $134-180$ & $126-146$ \\
\hline
\end{tabular}

\subsection{Experimental results}

\subsubsection{Velocity profile and friction coefficient}

Figs. 4 (a) and (b) show velocity profiles measured in the laboratory experiments with fine sand and silt, respectively. Here, that in the experiments with very fine sand is omitted. These figures also contain velocity profiles of clear-water flow. It is found that flow velocity decreases with sediment concentration in the experiments with fine sand (fig. 4 (a)). In the experiments with very fine sand, flow velocity increases with sediment concentration. Especially at $C_{T}=0.401$, very fast flow occurs. In the experiments with silt (fig. 4 (b)), flow velocity increases with sediment concentration. At $C_{T}=0.369$, however, rapid decrease in flow velocity and increase in flow depth occurs; the velocity profile is like that of Bingham-fluid flow.

Fig. 5 shows the relationship between friction coefficient $f=8(u * / v)^{2}$ and sediment concentration $C_{T}$. Here $u_{*}=$ friction velocity and $v=$ average velocity. This figure also contains the field data at the Kuye, Tuwei and Jialu River. It is found that the laboratory data have larger values than the field data within the range such that $0<C_{T}<0.3$. Within the range such that $C_{T}>0.3$, however, flow 
resistance coefficient $f$ has different values in each condition. Laboratory experiments using silt have very large values of $f$, but those using very fine sand have the very small values, which correspond to the discussion of velocity profiles (fig. 4).

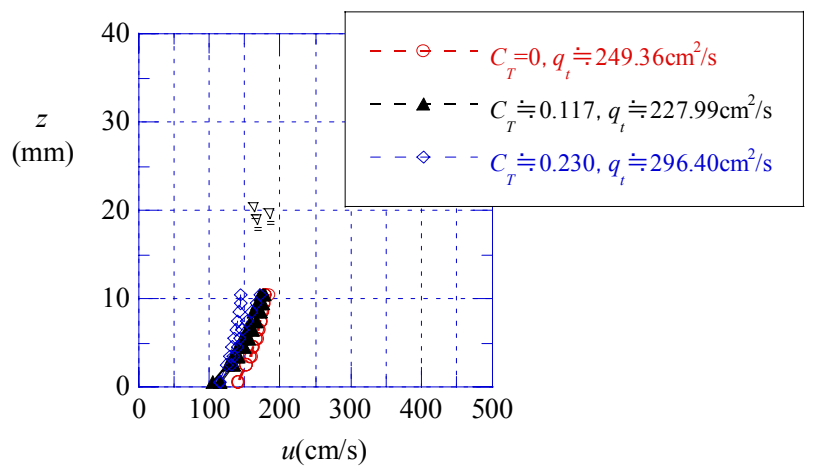

(a) Mixture flow of fine sand and water

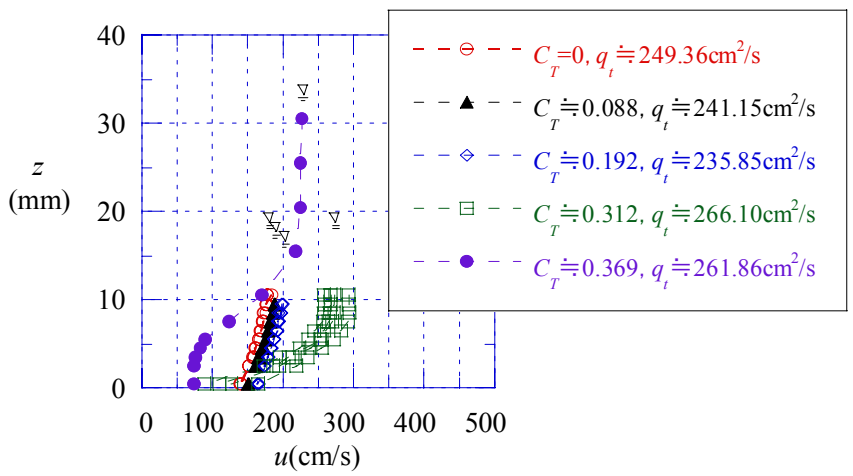

(b) Mixture flow of silt and water

Figure 4: Velocity profiles.

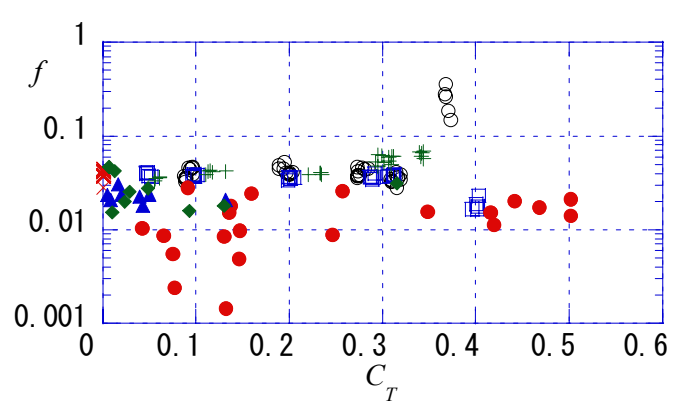

Figure 5: Relationship between friction concentration.
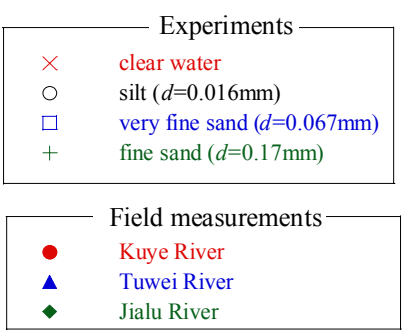

\footnotetext{
(1)
}

coefficient an

and sediment 

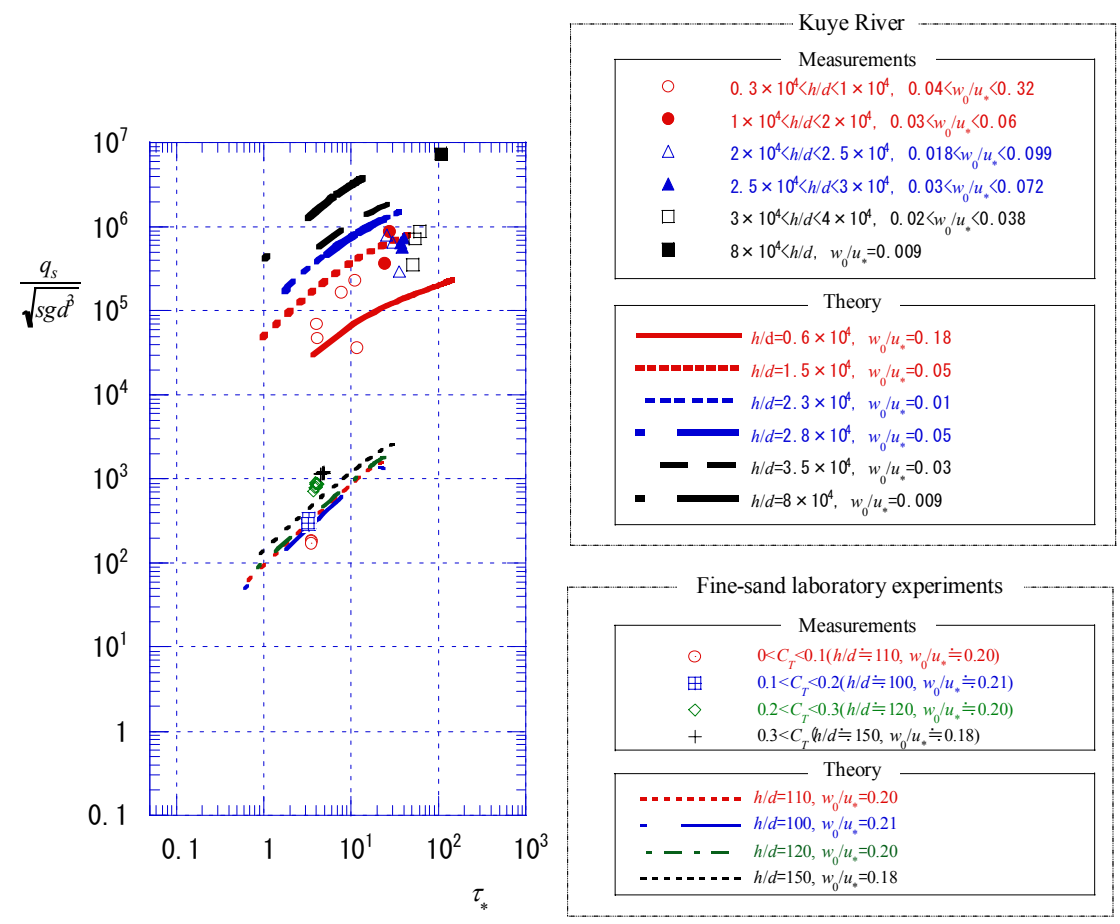

Figure 6: Sediment discharge measured in the Kuye River and the laboratory experiments with fine sand.

\subsubsection{Sediment discharge}

Fig. 6 shows non-dimensional sediment discharge measured in the laboratory experiments and the Kuye River. Here, every line indicates calculation of the sediment discharge formula (Hashimoto et al. $[8,9]$ ) described in Chapter 4.

It is found that there is a big difference between non-dimensional sediment discharge of laboratory and field data; it is of order $10^{2}-10^{3}$ in the laboratory experiments and $10^{4}-10^{7}$ in the Kuye River. The laboratory experiments have hydraulic conditions such that $110<h / d<150, w_{0} / u_{*}=0.2$ and $3<\tau_{*}<5$, but the Kuye River has the conditions such that $3000<h / d<80000,0.01<w_{0} / u_{*}<0.1$ and $4<\tau_{*}<100$.

\section{Review of previous works on sediment-water mixture flow}

Hashimoto and Hirano [2, 3] and Hashimoto [4] derived a non-dimensional parameter in the discussion of flow behaviour of sediment-water mixtures. On the basis of the non-dimensional parameter, they introduced a two-layer model for the mixture flow; the lower layer is called 'granular sublayer' and the upper one 'inertial sublayer'. Using this model, they explained various flow behaviour 
of sediment-water mixtures. This chapter describes the review of their previous works.

\subsection{Velocity profile and friction coefficient}

Selecting elevation $z$ from the bed as length scale in the non-dimensional parameter yields non-dimensional elevation:

$$
N_{z}=\frac{z}{d} \sqrt{\frac{\rho_{t}}{\sigma F\left(C_{T}\right)}}
$$

where $d=$ diameter of sediment grains; $\sigma=$ density of sediment grains; $F\left(C_{T}\right)=$ a function of sediment concentration and $\rho_{t}=\sigma C_{T}+\rho\left(1-C_{T}\right)$.

Using the non-dimensional elevation and the mixing-length theory, Hashimoto and Hirano $[2,3]$ obtained velocity profile equations as

$$
\frac{u}{u_{*}}=\frac{\xi}{\sqrt{K_{z x}}} \frac{z}{d} \sqrt{\frac{\rho_{t}}{\sigma F\left(C_{T}\right)}}
$$

for $\frac{z}{d} \sqrt{\frac{\rho_{t}}{\sigma F\left(C_{T}\right)}} \leq 15$ and

$$
\frac{u}{u_{*}}=\frac{1}{\kappa} \ln \left(\frac{z}{d} \sqrt{\frac{\rho_{t}}{\sigma F\left(C_{T}\right)}}\right)+\frac{u_{\delta}}{u_{*}}-\frac{1}{\kappa} \ln 15
$$

for $\frac{z}{d} \sqrt{\frac{\rho_{t}}{\sigma F\left(C_{T}\right)}} \geq 15$.

Integrating eqns. (2) and (3) yields average velocity $v$ and friction coefficient $f$ :

$$
\frac{v}{u_{*}}=\sqrt{\frac{8}{f}}=\frac{1}{2} \frac{\xi}{\sqrt{K_{z x}}} N_{h}
$$

for $N_{h} \leq 15$ and

$$
\frac{v}{u_{*}}=\sqrt{\frac{8}{f}}=\frac{15}{2} \frac{\xi}{\sqrt{K_{z x}}} \frac{15}{N_{h}}+\left(\frac{u_{\delta}}{u_{*}}-\frac{1}{\kappa}\right)\left(1-\frac{15}{N_{h}}\right)-\frac{1}{\kappa} \ln \left(\frac{15}{N_{h}}\right)
$$

for $N_{h} \geq 15$. Here, $K_{Z X}=$ coefficient. The non-dimensional flow depth $N_{h}$ is defined as

$$
N_{h}=\frac{h}{d} \sqrt{\frac{\rho_{t}}{\sigma F\left(C_{T}\right)}}
$$

\subsection{Sediment discharge}

On the basis of the two-layer model, Hashimoto et al. [8,9] derived sediment discharge formula for various types of sediment transport:

$$
\frac{q_{s}}{\sqrt{s g d^{3}}}=\frac{\bar{u}_{\delta}}{u_{*}} \tau_{*}^{3 / 2}\left(1-\frac{\tau_{* c}}{\tau_{*}}\right) \frac{1}{\left(\alpha-I_{f}\right) \cos \theta} G\left(I_{f}, \frac{h}{d}, \frac{w_{0}}{u_{*}}\right)
$$


where $s=(\sigma-\rho) / \rho ; \tau_{*}=$ non-dimensional shear stress; $\tau_{*_{c}}=$ critical nondimensional shear stress; $\theta=$ bed slope angle; $I_{f}=$ friction slope; $w_{0}=$ fall velocity of sediment grains in water; $\alpha=0.875, \bar{u}_{\delta} / u_{*}=4.7$ and $G=$ a function of $I_{f}, h / d$ and $w_{0} / u_{*}$.

\section{Comparison between measurements and theory}

We obtain the data of flow and sediment discharge at the hydrological measurement stations of the Kuye, Tuwei and Jialu River (Yellow River Conservancy Commission [1]). This chapter describes a comparison of the laboratory and field measurements with the theory of the sediment-water mixture flow model.

\subsection{Velocity profile and friction coefficient}

A comparison between the laboratory measurements and theoretical calculations of velocity profiles shows their good agreement in the mixture flow with fine sand and disagreement in the other mixture flow.

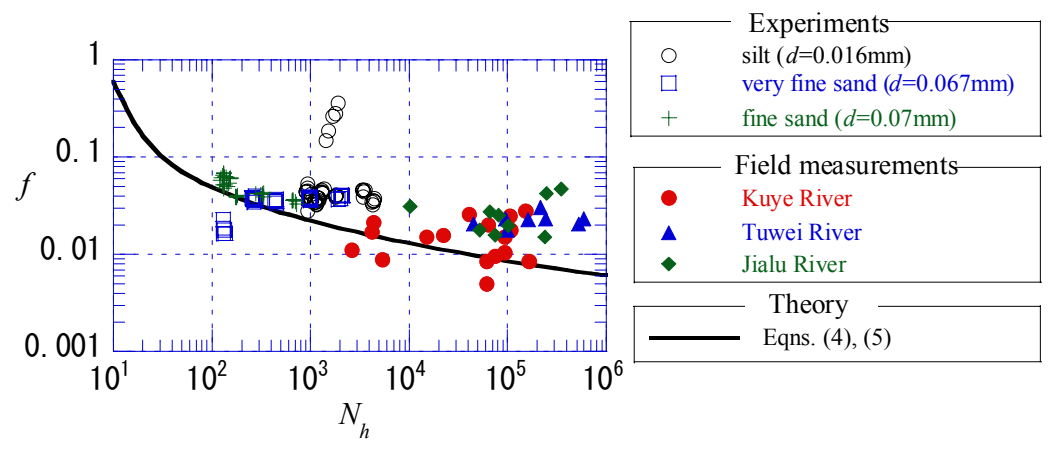

Figure 7: Relationship between friction coefficients $f$ and non-dimensional flow depth $N_{h}$.

Fig. 7 shows the relationship between friction coefficients $f$ and nondimensional flow depth $N_{h}$. The solid curve indicates the theoretical calculations of eqns. (4) and (5). The measurements in the Kuye River and the laboratory experiments with fine sand agree with the theoretical curve. However, the measurements in the Tuwei and Jialu River and the laboratory experiments with very fine sand and silt disagree with the theoretical curve.

Therefore, the mixture flow model (Hashimoto and Hirano [2, 3] and Hashimoto [4]) is found valid for flow resistance of the Kuye River and the finesand-water mixture. However, the model is also found inappropriate for the other mixture flow and the Tuwei and Jialu River. A different model is necessary for the Tuwei and Jialu River. 
The value of $N_{h}$ is of order $10^{2}-10^{3}$ in the laboratory experiments and $10^{4}-$ $10^{5}$ in the real rivers. Different values of $f$ in the laboratory experiments from those in the real rivers are attributed to different values of $N_{h}$ in each case.

\subsection{Sediment discharge}

Fig. 6 shows a comparison between the measurements in the laboratory experiments with fine sand and the Kuye River and the theoretical calculations of non-dimensional sediment discharge. From fig. 6 we can find good agreement between the measurements and the theory, although there is a big difference between the hydraulic conditions of the Kuye River and the laboratory experiments. Sediment transport in the Kuye River and laboratory experiments with fine sand can be explained satisfactorily by the mixture flow model of Hashimoto and Hirano [2, 3] and Hashimoto [4].

However, the model is inappropriate for the mixture flow with very fine sand and silt. It is also inappropriate for the Tuwei and Jialu River.

\section{Conclusions}

The results obtained in this study are as follows:

(1) Bed sediments are sand in the Kuye River and silt in the Dali River.

(2) Flow velocity decreases with sediment concentration in the experiments with fine sand. In the experiments with very fine sand, however, flow velocity increases with sediment concentration. Especially at $C_{T}=0.401$, very fast flow occurs. In the experiments with silt, flow velocity increases with sediment concentration. At $C_{T}=0.369$, however, rapid decrease in flow velocity and increase in flow depth occurs; the velocity profile is like that of Bingham-fluid flow.

(3) Flow resistance and sediment transport in the Kuye River and the laboratory experiments with fine sand can be explained satisfactorily by the mixture flow model of Hashimoto and Hirano [2, 3] and Hashimoto [4]. However, the model is inappropriate for the Tuwei and Jialu River and the laboratory experiments with very fine sand and silt. Thus, a different model is necessary for the Tuwei and Jialu River.

\section{Acknowledgements}

This study has been supported by the Core Research for Evolutional Science and Technology (CREST) program of Japan Science and Technology Agency (JST). The authors would like to appreciate their grant in aid on this study.

\section{References}

[1] Yellow River Conservancy Commission. Data of Water and Sediment of the Yellow River, 1980, 1982. 
[2] Hashimoto, H. \& Hirano, M. Resistance Rule of Mud Flows on Movable and Fixed Beds. Annual Journal of Hydraulic Engineering, JSCE, Vol. 39 pp. 495-500, 1995 (in Japanese).

[3] Hashimoto, H. \& Hirano, M. A Flow Model of Hyper-concentrated SandWater Mixtures. Debris-Flow Hazards Mitigation: Mechanics, Prediction, and Assessment, Proceedings of First International Conference, ASCE, August 7-9, pp. 464-473, 1997.

[4] Hashimoto, H. Flow Characteristics of Sediment-Water Mixtures in an Open Channel. The 20th Multiphase Flow Symposium pp. 61-68, 2001 (in Japanese).

[5] Wan, Z. \& Wang. Z., Hyper-concentrated Flow. IAHR/AIRH MONOGRAPH, 1994.

[6] Mantz. Peter A. Highly Concentrated Sediment Loads of the Yellow River. Proceedings of the International Symposium on Sediment Transport Modeling, pp. 411-416, 1989.

[7] Li, C. Field Investigation of Soil Erosion and Sediment Yield in the Loess Plateau of China, Sino-Japan Joint Academic Trip Report. 2002.

[8] Hashimoto, H., Park, K., Ikematsu, S. \& Tasaki, N., A Sediment Discharge Formula for Various Types of Sediment Transport in a Steep Open Channel. Annual Journal of Hydraulic Engineering, JSCE, Vol.47 pp. 571-576, 2003 (in Japanese).

[9] Hashimoto, H., Takaoka, H. \& Park, K. Sediment Discharge Formula for Steep Open Channel. Proceedings of the Ninth International Symposium on River Sedimentation, Vol. 3. pp. 1453-1461, 2004. 